\title{
Construction of renewable energy supply chain model based on LCA
}

https://doi.org/10.1515/phys-2018-0132

Received October 24, 2018; accepted November 14, 2018
Abstract: The current building's energy supply chain model has the characteristics of high complexity, timeconsuming, poor accuracy, and high pollution coefficient. In this paper, a renewable building's energy supply chain model based on LCA is proposed. Based on the definition of planned supply chain, procurement, construction and delivery process, the operation reference model of renewable green building's energy supply chain is analyzed. According to the analysis of LCA, the life cycle stage set of renewable green building's energy supply chain is obtained. A renewable green building's energy supply chain model with economic and low-carbon comprehensive objectives is obtained by combining the economic goal-oriented model with the low-carbon goal-oriented model and introducing the life cycle stage set. The experimental results show that the modeling complexity of the model is low and the time-consuming is less. The model fits the actual situation well. The pollution coefficient of the model is smaller than that of the current model. It is practical and provides technical reference for the field of green building.

Keywords: LCA; green building; renewable; building's energy; supply chain; model

PACS: 88.05.Ec, 07.05.Tp, 82.20.Wt

Lei Luo: College of Architecture Engineering, Huangshan University, Huangshan 245041, China, E-mail: jndkhkiu@163.com *Corresponding Author: Liu Yang: College of Architecture, Xi'an University of Architecture and Technology, Xi'an 710055, China, E-mail: zrl1807@163.com

Marlia Mohd Hanafiah: School of Environmental and Natural Resource Sciences, Faculty of Science and Technology, Universiti Kebangsaan Malaysia UKM Bangi, Selangor, Malaysia,

E-mail:mhmarlia@ukm.edu.my

\section{Introduction}

There are many different characteristics between the construction industry and other industries. The current construction enterprises generally lack the mechanism to evaluate the performance of supply chain operation as a whole in order to optimize the state. It is very likely that the construction enterprises cannot achieve the best performance by using the construction supply chain management, and it will also make that the development of construction supply chain's management software falls into the "IT black hole" $[1,2]$.

Therefore, scientific and quantitative evaluation of the performance of each business process in the supply chain of construction enterprises, to find out the operation link of poor performance, improve the business process, and develop a supply chain operation reference model based on business process is the indispensable prerequisite for improving the performance of green building's supply chain management. The construction industry is the pillar industry of China's national economy, but the production efficiency of China's construction projects is relatively low. And due to the delay of construction period, waste of resources, the conflict between the various parties to resolve improper, poor management and other reasons, many construction enterprises lack of core competitiveness. With the opening of China's green construction market, it is imminent to improve the competitiveness of China's construction enterprises. Facts have proved that the emerging supply chain management can effectively reduce enterprise operating costs, improve efficiency and enhance the core competitiveness of enterprises, so the concept of construction supply chain has been proposed at home and abroad [3, 4]. As one of the effective tools to improve the performance of the supply chain, green building's energy supply chain model has been studied by many scholars. However, there are few research results on the energy supply chain model of green building industry in China, so it is necessary to do further research.

Zhu Xiaolong et al. put forward an iron and steel supply chain model based on the epsilon constraint method and interval number linear programming. Due to the exis- 
tence of secondary energy, the energy flow in the steel supply chain interacts with each other in different processes, and there is a positive and reverse energy flow. Optimizing the energy flow in the steel supply chain can significantly improve the utilization efficiency of secondary energy, thus reducing the comprehensive energy consumption of steel enterprises. Firstly, the energy flow in iron and steel supply chain was studied, and the energy flow model of iron and steel supply chain was established. On this basis, the energy optimization model of iron and steel supply chain was constructed by considering the dual objectives and related constraints of energy optimization in iron and steel supply chain. Finally, a typical example was given to show that the model could effectively reduce the energy consumption of iron and steel enterprises, but the complexity of the model construction was high [5]. Peng Xiaofeng et al. put forward the building's supply chain model based on CODP theory and BIM technology. According to the idea of supply chain management, CODP classification rules were introduced, and the theoretical framework of modeling was put forward. At the operational level, the implementation of supply chain modeling and simulation in BIM environment was discussed, and at the strategic level, the early warning management method of BIM project supply classification based on CODP was proposed. The purpose was to provide accurate, complete and real-time supply and logistics information for construction project management, in order to better achieve the objectives of project management. The model was relatively simple, but the environmental problems were not considered in the process of making the model, and the pollution coefficient was large after the model was implemented [6]. Wei Xia et al. put forward a PSP/IQ based index system to evaluate information quality in supply chain. Based on the relevant theory of information quality, a method of constructing information quality evaluation index in supply chain was established by using PSP/IQ model. Through the PSP/IQ model, the indicators were analyzed, and classified into the corresponding four first-level indicators, the evaluation index framework was established. By introducing network analytic hierarchy process, through questionnaire survey, expert scoring and other methods, the weight of information quality indicators was calculated from qualitative and quantitative aspects. Finally, a relatively complete evaluation standard for information quality of supply chain was established. The model was more comprehensive, but taken a long time [7]. Zhang Jie et al. put forward an enterprise supply chain model based on Petri net. modeling and analyzing the perturbation problem in supply chain of manufacturing enterprises, and the main research contents included the following aspects: hi- erarchical integrated modeling of supply chain system of manufacturing enterprises based on Petri nets was carried out; the accessibility analysis of Petri net was used to analyze the objectives of supply chain system, once perturbation occurred, Petri net node algorithm was used to analyze the influence of disturbance on the system objectives and the strategies to deal with the disturbance, so as to provide the basis for enterprise decision makers; and the effectiveness of the method was verified by an example of supply chain in manufacturing enterprises. The model had strong stability, but the accuracy of model building was poor [8].

Aiming at the problems existing in the current models, a renewable building's energy supply chain model based on LCA is proposed. The detailed process is as follows:

The operation reference model of renewable green building's energy supply chain is analyzed to lay a foundation for the construction of renewable green building's energy supply chain model based on LCA.

The life cycle stages of renewable green building's energy supply is defined and gotten.

The model of renewable green building's energy supply chain based on LCA is constructed with the economic goal-oriented model and the low-carbon goal-oriented model.

The overall performance of the proposed model is verified by experiments and discussions.

The full text is summarized and the next research plan is proposed.

\section{Methods}

\subsection{Operation reference model analysis of renewable green building's energy supply chain}

Planned supply chain: the planned supply chain process consists of four process elements, as shown in Figure 1. As the general contractor may contract more than one project at a time, first of all, according to the design drawings of each project, as well as the previous planning data and revised forecast data, the general contractor should determine the supply chain demand information of all the projects to be built and under construction, and sort and aggregate the requirements according to their importance [9]. Then, according to the existing inventory, material plan, financial plan, human resources plan, construction plan, delivery plan, their own production capacity, subcontracting plan and adjusted supply chain demand 
information, the resources of the entire supply chain is determined, and the various resources according to the importance are sorted and aggregated. After summing up the demand and resources of the supply chain, it can balance the supply and demand according to the enterprise's strategic policy, and finally establish and communicate the supply chain plan.

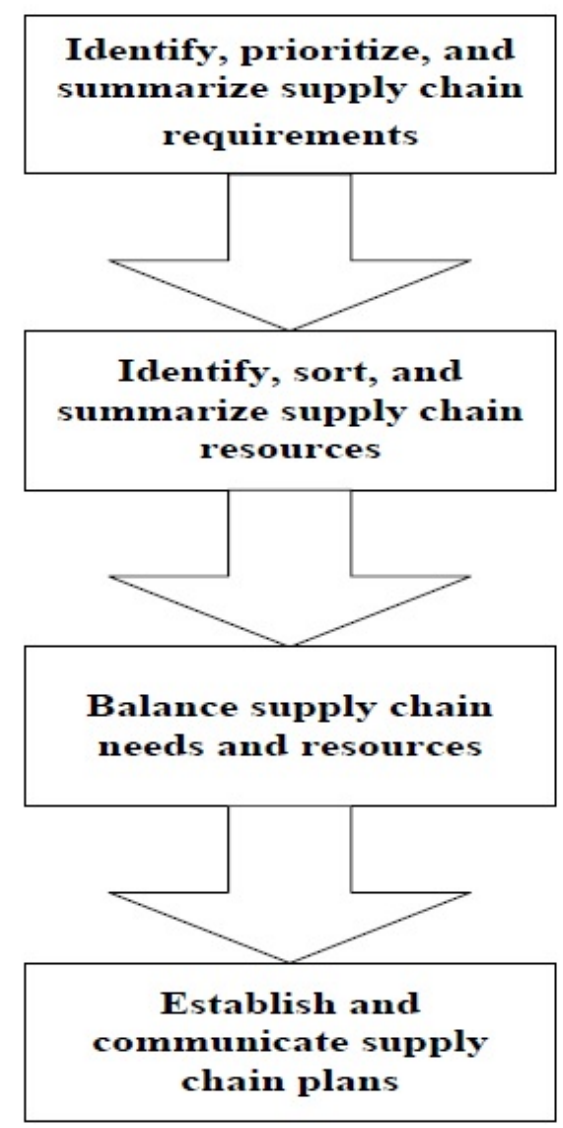

Figure 1: Process of the planned supply chain

Procurement: procurement includes four process elements, as shown in Figure 2. The general contractor determines the resources needed to complete the construction products according to the established supply chain plan, construction plan, delivery plan, material plan, schedule plan, and so on, and sorts and aggregates the resources required according to their importance. At the same time, the resources available, such as manpower, materials, funds and the products and services provided by the suppliers are determined, and the resources according to their importance are sorted and aggregated. Then the demand and resources are balanced, and finally the procurement plan is established.

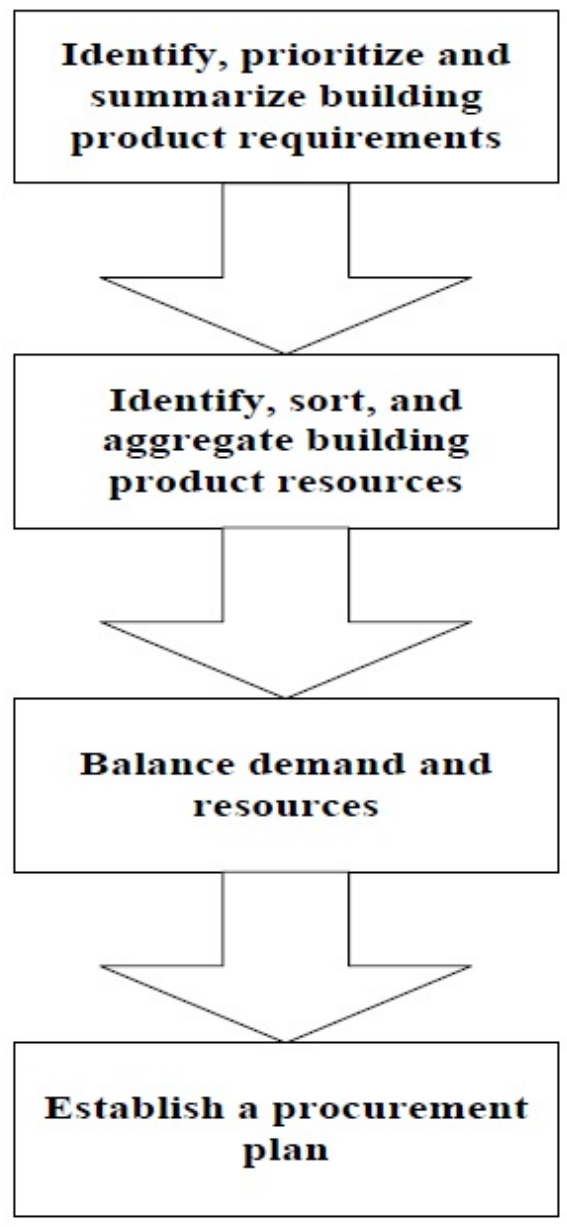

Figure 2: Procurement process

Construction: construction also includes four similar process elements, as shown in Figure 3. The general contractor determines, sorts and aggregates the construction requirements according to the established supply chain plan, delivery plan, material plan, schedule, etc. The general contractor determines and aggregates the construction resources according to the purchase plan, plan data, schedule plan and existing inventory, and then balances the needs and resources according to the enterprise strategic policy. Finally, the construction plan is established to determine the production activities within a specific period of time and effectively allocate resources to meet the construction needs.

Delivery: the delivery process includes the following four process elements, as shown in Figure 4. The general contractor determines, ranks and aggregates the delivery requirements according to the data of the owner's demand, supply chain plan, service level and production schedule. Meanwhile, according to the data of the purchase plan, construction plan, existing inventory, exist- 


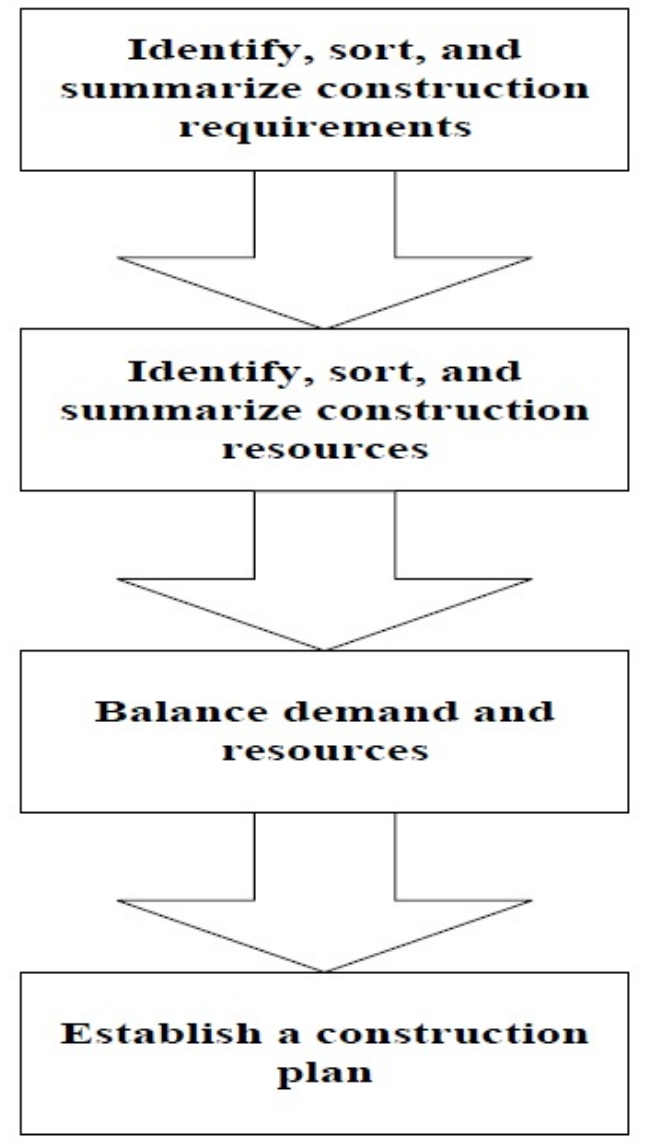

Figure 3: Construction process

ing resources and delivery time, the resources needed for timely and quantitative delivery are determined, sorted and aggregated, then to balance demand and resources. Finally, the delivery plan is established.

\subsection{LCA analysis}

LCA is a comprehensive assessment method of environmental impact based on the whole life cycle. In the definition of LCA, the definition of objectives and scope is a very important first step, which needs to determine the representative value and accuracy of the assessment. There are two purposes for LCA analysis within the scope of mathematical programming. One is to optimize the environment, in which LCA is used as an endogenous tool to compare alternative topologies of the same network; the other is to compare the environmental performance of new and traditional network structures using the results of optimization [10]. Here, we define the lifecycle stages of renewable green building's energy supply as in Figure 5 .

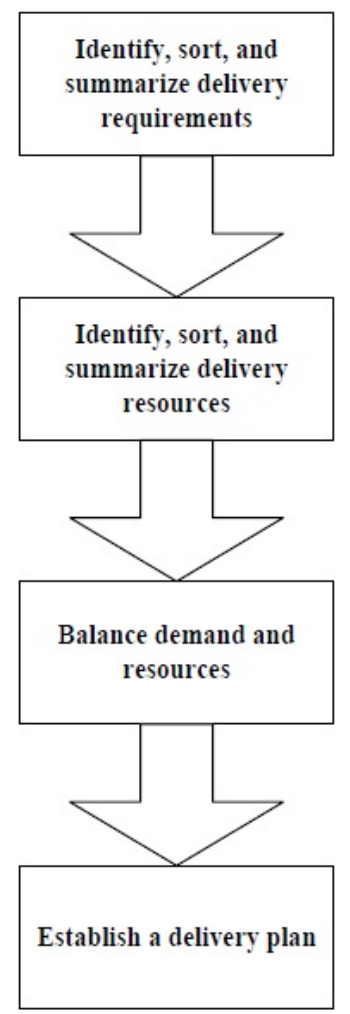

Figure 4: Delivery process

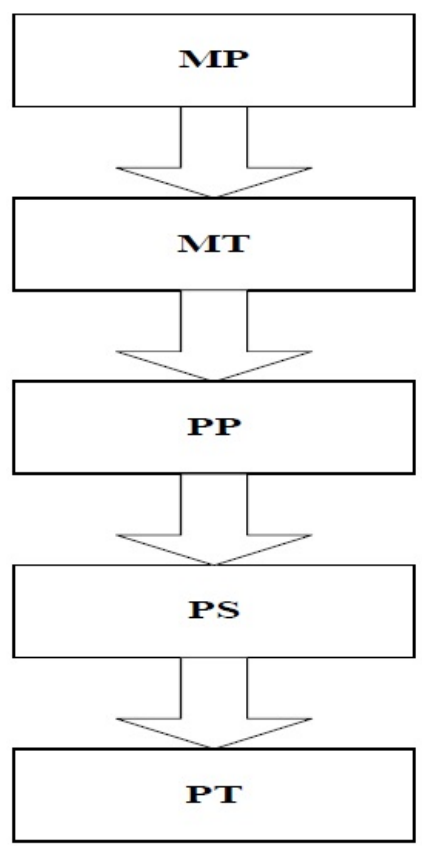

Figure 5: Schematic diagram for each stage of LCA

According to Figure 5, the life cycle stage set $s$ of the whole renewable green building's energy supply chain can 
be described as follows:

$$
s=\{M P, M T, P P, P S, P T\}
$$

where $M P$ represents raw material production, $M T$ represents raw material transportation, $P P$ represents product production, $P S$ represents product storage, and $P T$ represents product transportation.

\subsection{A renewable energy supply chain model based on LCA}

Based on the analysis results of Section 2.1 and 2.2, a threelevel supply chain is simulated. The raw material flow between suppliers, purchasers and green energy plants is carried out by different means. Green energy plants could produce products by different processes. The carbon emission cost is taken as a part of the supply chain cost. Considering the raw material output and the constraints of the national energy-saving and emission-limiting policies, a single objective optimization decision-making problem, i.e. the minimization of the total cost of the raw material supply chain, is proposed. The following assumptions are made:

(1) Only the operation of the supply chain within one cycle is considered;

(2) The discrepancy caused by external factors such as natural disasters and climate change will not be considered.

(3) Green energy plants are located in the central area of the region and collected within a certain radius of the region;

(4) Green energy procurement and product sales channels are fixed.

(5) The rental of premises and warehouses will remain unchanged.

(6) The demand of the processing plant can be satisfied without importing raw materials from other fields.

(7) Carbon emissions are only related to transport distance among different transport nodes.

According to the above assumptions, the complexity and the modeling time of building the renewable green building's energy supply chain model are reduced. The construction of renewable green building energy supply chain model based on LCA is completed. The detailed process is as follows:

1) Establishment of an economic goal oriented model:

Depreciation cost of fixed assets:

$$
\begin{gathered}
I N V=E Q U+H O U+P L A \\
B I N V=\frac{I N V}{T}
\end{gathered}
$$

where $N V$ represents the fixed assets of green building energy, $B I N V$ represents the depreciation cost of fixed assets, $E Q U$ represents the purchase cost of green building's equipment, $\mathrm{HOU}$ represents the construction cost of green building, PLA represents the rental cost of green building's energy sites, $T$ represents the service life.

Procurement cost is:

$$
P U R=\sum N_{g} \cdot U_{g}
$$

where PUR represents the cost of green building's energy procurement, $N_{g}$ represents the corresponding amount of $g$ green building's energy procurement, $U_{g}$ represents the unit cost of $g$ green building's energy procurement. The cost of renewable green building's energy procurement is related to the purchase price and quantity of energy units.

Transportation cost TRA:

$$
T R A=T R A_{1, g}+T R A_{2, g}+T R A_{3, g}
$$

where $T R A_{1, g}, T R A_{2, g}$ and $T R A_{3, g}$ represent the transportation of $g$ kinds of renewable green building's energy transportation costs mainly include three parts: transportation, loading and unloading costs and oil charges.

Inventory cost $S T O$ :

$$
S T O=\sum\left(P R E_{g} \cdot S T O_{g}+S T O_{g} \cdot S_{g}\right)
$$

Where $P R E_{g}$ represents the pretreatment cost of $g$ green energy unit, $S T O_{g}$ represents the inventory of $g$ green energy, $S_{g}$ represents the inventory cost of $g$ green energy unit.

The cost of taxation TAX:

$$
T A X=\sum Q_{h} R_{h} P_{o}
$$

where $Q_{h}$ denotes the number of the $h$ th green building's energy product, $R_{h}$ represents the unit price of the $h$ th green building energy, and $P_{o}$ represents the tax rate.

In summary, the total cost model $S C$ of renewable green building's energy supply chain is:

$$
S C=B I N V+P U R+T R A+S T O+C O N+T A X+M B
$$

where, CON represents the daily management cost of green building's energy, and $M B$ represents the wages of workers.

2) Building the low carbon target oriented model

The carbon emission $C_{o}$ of renewable green building's energy in procurement sector is:

$$
C_{o}=\sum D_{g} \cdot C_{m, g}
$$

where $D_{g}$ represents the transportation distance of $g$ kinds of green energy, $C_{m, g}$ represents the carbon emission per unit distance of $g$ kinds of green energy. 
The carbon emission $C_{y}$ of renewable green building's energy in the transport link is:

$$
C_{y}=C_{a}+C_{b}
$$

where $C_{a} \infty$ stands for the carbon emissions during transportation and $C_{b}$ represents carbon emissions during loading and unloading. Total carbon emissions are directly related to total green energy consumption during transportation, indirectly related to transport distance, transport volume and transport green energy consumption per unit [12].

The carbon emission $C_{d}$ in storage link is:

$$
C_{d}=\sum S T O \cdot \omega_{q} \cdot T_{q} \cdot V_{q}
$$

where $\omega_{q}$ represents the potential value of greenhouse gas emission of $q$ gases, $T_{q}$ represents the time of greenhouse gas emission of $q$ gases, and $V_{q}$ represents the greenhouse gas emission rate of $q$ gases. Carbon emissions from storage links are related to energy storage, greenhouse gas emission rate and emission time [14-21].

In summary, the greenhouse gas emission model $C_{t o}$ of renewable green building's energy supply chain is:

$$
C_{t o}=C_{o}+C_{y}+C_{d}+C_{f}+C_{q}
$$

where $C_{f}$ represents carbon emissions in production, and $C_{q}$ represents carbon emissions from workers' activities. Through the consideration of air pollution, we can reduce the pollution index of renewable green building's energy supply.

According to the analysis and calculation of 1) and 2), the building's energy supply chain model oriented by the comprehensive objective of economy and low carbon can be expressed as follows:

$$
Z=\lambda\left[S C+C_{t o} \cdot P_{C}\right] s
$$

In Eq. (13), $\lambda$ represents the impact parameters of normal operation of the renewable green building's energy supply chain, the value is controlled at $[1.3,1.4]$, renewable green building's energy supply chain is the most perfect, with the highest modeling accuracy. $Z$ represents the renewable green building's energy supply chain model based on LCA.

\section{Results}

The renewable green building's energy supply chain model based on LCA is applied to Construction Company A to verify the feasibility of the proposed model. The indicators are as follows:
Complexity of model building

Time consuming in model building

Enterprise pollution coefficient after model realization

Accuracy of model building

The results are as follows:

Experiment 1:

\section{Experiment 2:}

Figures 6 and 7 show the analysis, before constructing the renewable green building's energy supply chain model based on LCA. A series of assumptions are put forward, such as only considering the supply chain operation in one cycle, the purchase of raw materials, the fixed sales channels of products, the constant rental costs of warehouses and venues. These assumptions not only reduce the complexity of building the model. They also reduce the time consuming of model building.

\section{Experiment 4:}

In Figure 9, the current model is lower than the actual situation, that is, the modeling accuracy is low. The renewable green building energy supply chain model based on LCA is constructed by introducing the influence parameters of the normal operation of the renewable green building's energy supply chain, and controlling them within a reasonable range, which enhances the accuracy of building's energy supply chain model.

\section{Discussion}

Taking the influence parameter $\lambda$ in the normal operation of the renewable green building's energy supply chain as the object of discussion, and observing that the value is controlled at [1.3, 1.4], the renewable green building's energy supply chain is the most perfect, that is, the modeling accuracy is the highest. The observation platform is built on MATLAB, and the $\lambda$ value is defined in the interval $[1.3,1.4]$ and $[1.5,1.6]$, respectively. The results obtained are as follows:

In Figure 10, when the value of $\lambda$ is at $[1.3,1.4]$, the model of renewable green building's energy supply chain is in good agreement with the actual situation, and when the value of $\lambda$ is at $[1.36,1.38]$, the modeling accuracy is the highest; when the value of $W 2 L O K$ is at $[1.5,1.6]$, the modeling effect is not very ideal, and the highest degree of agreement between the model and the actual situation is $84 \%$. It can be seen that controlling of $\lambda$ at $[1.3,1.4]$ is correct in some extent. 


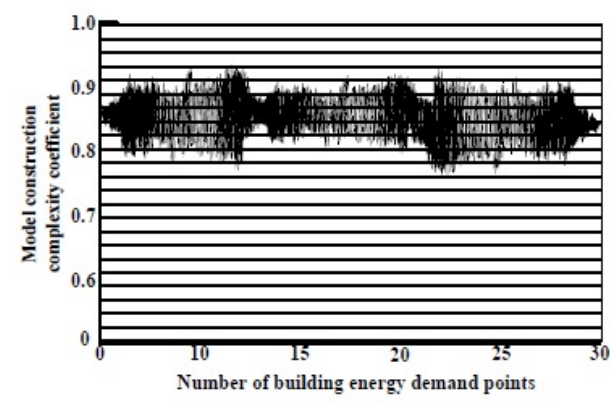

(a) Construction complexity of iron and steel supply chain model based on $\epsilon$-constraint method and interval number linear programming

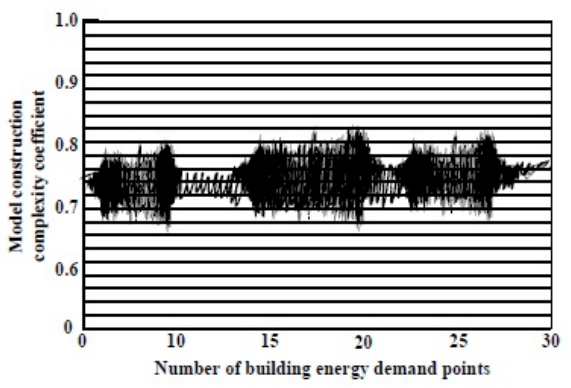

(b) Construction complexity of building supply chain model based on CODP theory and BIM technology

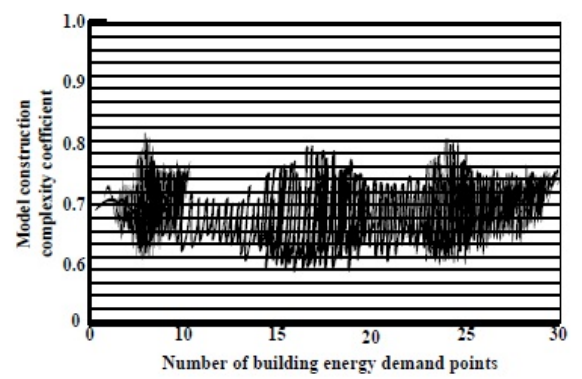

(c) Construction complexity of building supply chain model based on PSP/IQ measurement

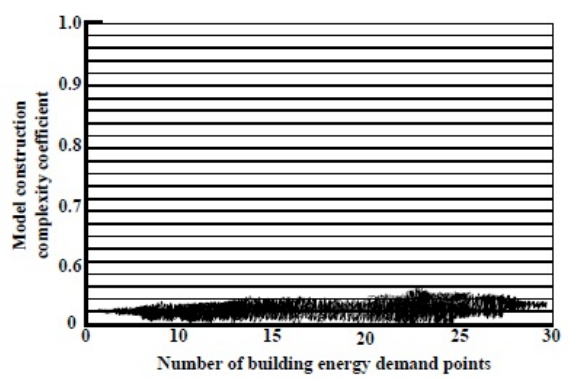

(d) Construction complexity of renewable green building's energy supply chain model based on LCA

Figure 6: Complexity comparison of different models

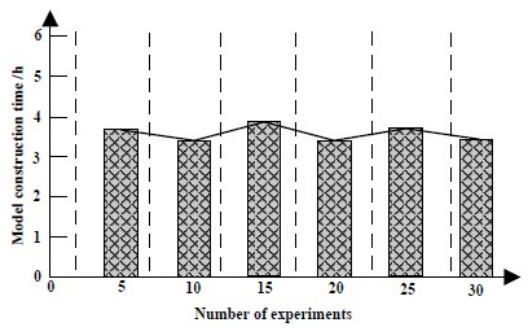

(a) Time-consuming construction of information quality measurement indicators in supply chain based on PSP/IQ

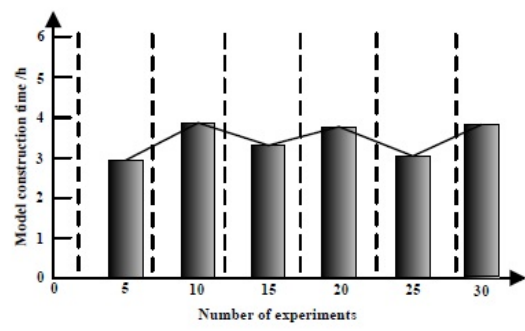

(b) Time-consuming of enterprise supply chain model construction based on Petri net

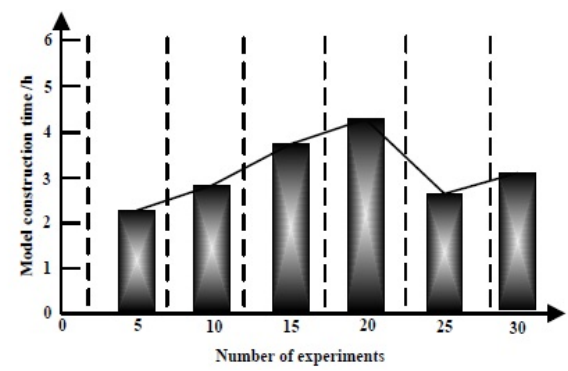

(c) Time-consuming of building's supply chain model construction based on CODP theory and BIM technology

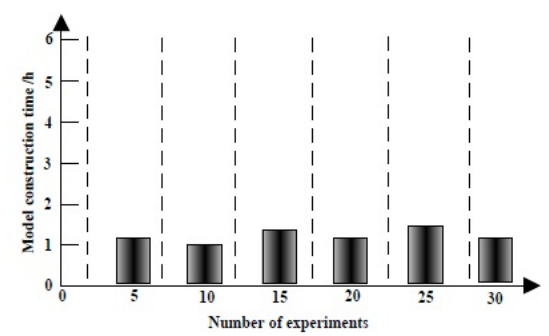

(d) Time-consuming of renewable green building's energy supply chain model construction based on LCA

Figure 7: Time-consuming comparison of different models 


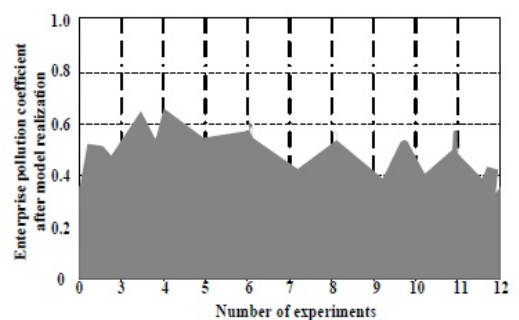

(a) The pollution coefficient after implementation of building's supply chain model based on CODP theory and BIM technology

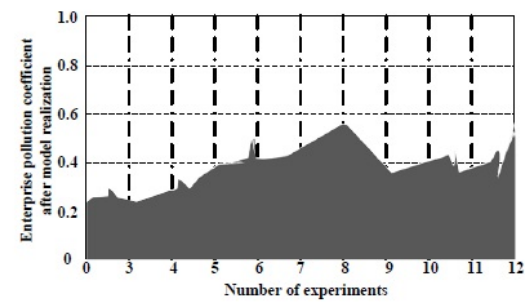

(b) The pollution coefficient after implementation of enterprise's supply chain model based on Petri net

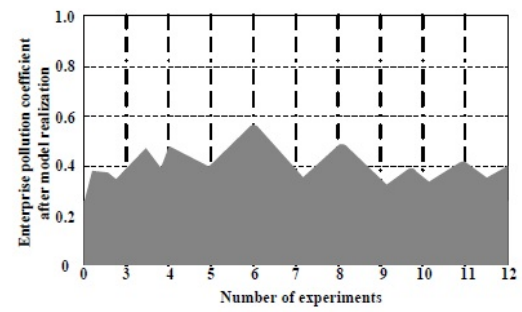

(c) The pollution coefficient after implementation of steel supply chain model based on the $\epsilon$-constraint method and interval number linear programming

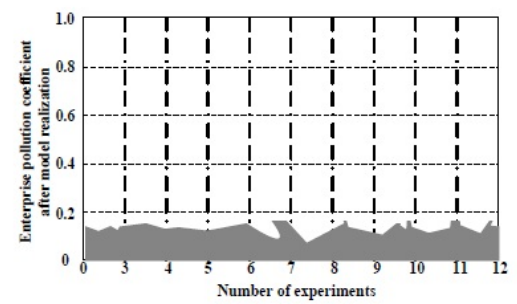

(d) The pollution coefficient after implementation of a renewable building's energy supply chain model based on LCA

Figure 8: Comparison of pollution coefficients after implementation of different models

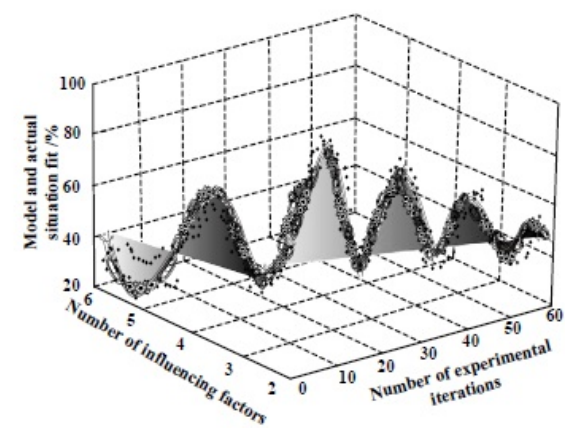

(a) The construction accuracy of enterprise supply chain model based on Petri net

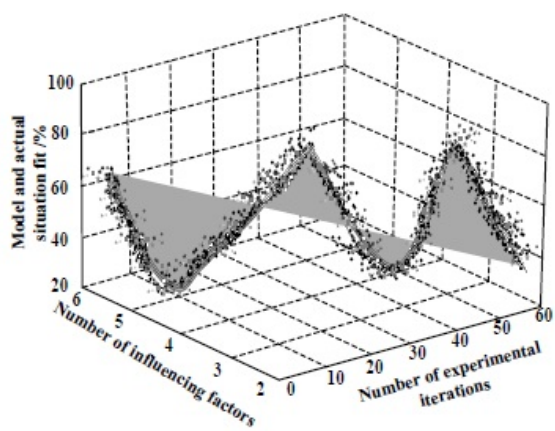

(b) The construction accuracy of building's supply chain model based on CODP theory and BIM technology

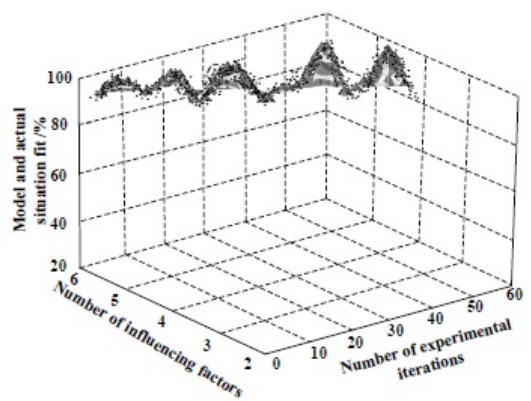

(c) The construction accuracy of renewable energy building's supply chain model based on LCA

Figure 9: Comparison of accuracy of different models

\section{Conclusions}

In view of the obvious global energy crisis, greenhouse gas effects and the strong appeal for environmental protection, a renewable building's energy supply chain model based on LCA is proposed from the perspective of economic benefits and green environmental protection. The 


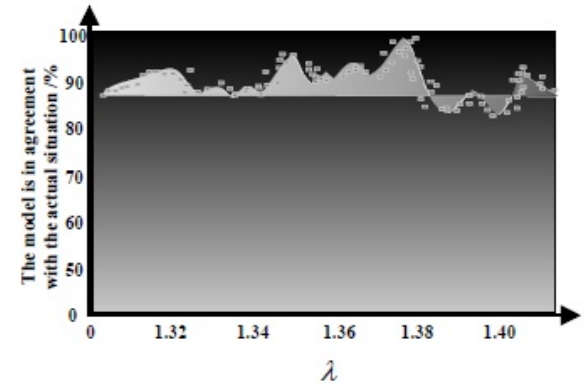

(a) The modeling effect when $\lambda$ value is defined at $[1.3,1.4]$

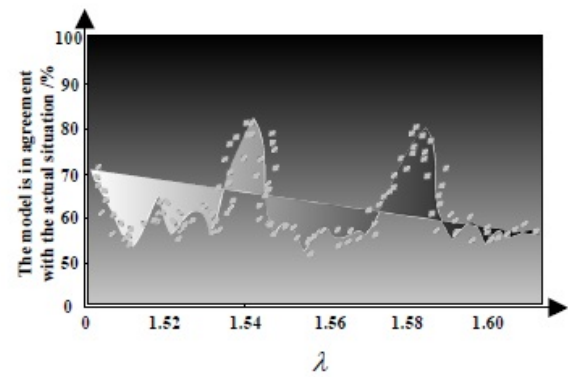

(b) The modeling effect when $\lambda$ value is defined at $[1.5,1.6]$

Figure 10: The influence of different $\lambda$ values on building's renewable energy supply chain model

model is constructed by combining quantitative and qualitative analysis. The reliability of the proposed model is verified by experiments and discussions, and the following suggestions are put forward for the next research: due to the limitations of data acquisition, there are still some errors in modeling accuracy, which can be improved in the next step. The above research object is renewable green building's energy supply chain supply chain, and the next step is to explore and expand the scope of research for nonrenewable green building's energy.

Acknowledgement: Natural Science Foundation of Anhui Provincial Department of Education - General project (KJHS2015B13)

\section{References}

[1] Chiu C.H., Choi T.M., Supply chain risk analysis with Meanvariance models: A Technical Review, Annals Oper. Res., 2016, 240(2), 489-507.

[2] Zhang P., Qin Z.C., Lu Z., An analytical model of space backbone network capacity for space information transmission, J. China Acad. Electr. Inform. Techn., 2016, 11(1), 66-72.

[3] Li B.X., Xie J.Y., Contract strategies and innovation investment of competing supply chain with spillovers effects, Bulletin Sci. Techn., 2017, 33(6), 32-37.

[4] Wei G.L., Chen Z.J., A product reliability evaluation method based on multi-stress comprehensive acceleration model, Sci. Technol. Eng., 2016, 16(2), 24-29.

[5] Zhu X.L., Ding S., Zhu W.L. et al., An energy optimization model of iron and steel supply chain using $\epsilon$-Constraint method and interval linear programming approach, J. Industr. Eng. Eng. Manag., 2016, 30(2), 243-250.

[6] Peng X.F., Zeng N.S., Mao C., Modeling and simulation of construction supply chain based on CODP theory and BIM technology, Constr. Technol., 2016, 45(18), 33-37.

[7] Wei X., Fan H.S., Ren M.M. et al., Research and construction of information quality index system of supply chain based on PSP/IQ model, Modern. Manag., 2017, 37(1), 95-97.

[8] Zhang J., Li M., Disruption analyzing modeling of manufacturing supply chain based on petri nets, Industr. Technol. Economy, 2017, 36(2), 126-132.

[9] Lei Z.M., Liu C., Liao W.Z. et al., Optimal management for iron and steel enterprise logistics inventory resources scheduling, Comput. Simul., 2017, 34(7), 395-399.

[10] Zhang S.F., Cloud computing collaborative management technology of supply chain based on personalized data mining, Comput. Meas. Contr., 2017, 25(6), 261-263.

[11] Sahay N., lerapetritou M., Multienterprise supply chain: simulation and optimization, Aiche J., 2016, 62(9), 3392-3403.

[12] Dev N.K., Shanka R., Gunasekaran A. et al., A hybrid adaptive decision system for supply chain reconfiguration, Int. J. Prod. Res., 2016, 54(23), 7100-7114.

[13] Luo R.S., Design of drug supply chain management system based on RFID technology, Autom. Instrument., 2017, (6), 84-85.

[14] Chen L., Peng J., Liu Z. et al., Pricing and effort decisions for a supply chain with uncertain information, Int. J. Prod. Res., 2017, 55(1), 264-284.

[15] Zhang Y.X., Li H.E., Design and implementation of material supply monitoring platform based on J2EE, Electr. Design Eng., 2017, 25(17), 65-68.

[16] Patra S., Dhote V.W., Sarkar S., Samanta A., Evaluation of novel insecticides against diamondback moth and natural enemies in cabbage ecosystem, J. Environm. Biol., 2017, 38(6), 1383-1389.

[17] Shiralashetti S., Mundewadi R.A., Modified wavelet fullapproximation scheme for the numerical solution of nonlinear volterra integral and integro-differential equations, Appl. Math. Nonlin. Sci., 2016, 1(2), 529-546.

[18] Li Z., Han C., Wei D., Empirical research on the relationship between natural gas consumption and economic growth in the northeast Asia, Ener. Environ., 2018, 29(2), 216-231.

[19] Ge S.B., Ma J.J., Jiang S.C., Liu Z., Peng W.X., Potential use of different kinds of carbon in production of decayed wood plastic composite, Arab. J. Chem., 2017.

[20] Attia G.F., Abdelaziz A.M., Hassan I.N., Video observation of perseids meteor shower 2016 from Egypt, Appl. Math. Nonlin. Sci., 2017, 2(1), 151-156.

[21] Kylili A., Fokaides P.A., loannides A., Kalogirou S., Environmental assessment of solar thermal systems for the industrial sector, J. Cleaner Prod., 2018, 176, 99-109. 